University of Nebraska - Lincoln

DigitalCommons@University of Nebraska - Lincoln

1995

\title{
Repeatability of Maximal Aerobic Performance in Belding's Ground Squirrels, Spermophilus beldingi
}

\author{
M. A. Chappell \\ University of California - Riverside \\ Gwendolyn C. Bachman \\ University of Nebraska - Lincoln, gbachman@unl.edu \\ J. P. Odell \\ University of California - Riverside
}

Follow this and additional works at: https://digitalcommons.unl.edu/bioscifacpub

Part of the Life Sciences Commons

Chappell, M. A.; Bachman, Gwendolyn C.; and Odell, J. P., "Repeatability of Maximal Aerobic Performance in Belding's Ground Squirrels, Spermophilus beldingi" (1995). Faculty Publications in the Biological Sciences. 222.

https://digitalcommons.unl.edu/bioscifacpub/222

This Article is brought to you for free and open access by the Papers in the Biological Sciences at DigitalCommons@University of Nebraska - Lincoln. It has been accepted for inclusion in Faculty Publications in the Biological Sciences by an authorized administrator of DigitalCommons@University of Nebraska - Lincoln. 
Published in Functional Ecology (1995) 9: 498-504. Copyright 1995, Springer. Used by permission.

\title{
Repeatability of Maximal Aerobic Performance in Belding's Ground Squirrels, Spermophilus beldingi
}

\author{
M. A. Chappel, ${ }^{*}$ G. C. Bachman** and J. P. Odell* \\ *Biology Department, University of California, Riverside, California, U.S.A. \\ **Department of Biology, University of California, Los Angeles, California, U.S.A.
}

Summary

1. The repeatability of a trait is a critical factor in determining how that trait is affected by natural selection. We examined the repeatability of a key physiological trait, maximum oxygen consumption $\left(\mathrm{VO}_{2 \max }\right)$, in a wild population of Belding's Ground Squirrels, Spermophilus beldingi. $\mathrm{VO}_{2 \max }$ is an integrated measure of organismal metabolic performance. It can be intuitively related to fitness because it sets an upper limit to sustainable power output during ecologically important activites such as locomotion and thermoregulatory heat production.

2. We used respirometry to determine $\mathrm{VO}_{2 \max }$ during exercise and thermogenesis. Exercise $\mathrm{VO}_{2 \max }$ was elicited in an enclosed running wheel. Thermogenic $\mathrm{VO}_{2 \max }$ was obtained with acute cold exposure in a helium-oxygen gas mixture.

3. Repeatability of both exercise and thermogenic $\mathrm{VO}_{2 \max }$ was high over $2 \mathrm{~h}$ intervals but declined over longer test periods (6-18 days and 1-2 years). In general, repeatability was higher for exercise $\mathrm{VO}_{2 \max }$ than for thermogenic $\mathrm{VO}_{2 \max }$.

4. We found no repeatability for animals tested initially as juveniles and then 1 or 2 years later as adults; evidently there is sufficient plasticity in $\mathrm{VO}_{2 \max }$ to decouple aerobic performance between these life stages. A small number of adults tested in successive years showed significant repeatability of exercise $\mathrm{VO}_{2 \max }$ but no repeatability of thermogenic $\mathrm{VO}_{2 \max }$.

Keywords: Aerobic capacity, Between-individual variation, Exercise, Phenotypic plasticity, Thermogenesis

Introduction

In recent years physiological ecologists have shown increasing interest in the repeatability of individual variation in physiological traits, particularly for aspects of whole-animal performance that can be intuitively linked to fitness. Repeatability data obtained over different intervals yield insights into the consistency, or otherwise, of individual performance over time. An understanding of the amount of phenotypic plasticity vs long-term individual consistency of physiological performance is crucial for studies of adaptation and evolution, because repeatability is a major factor in determining how a trait will be affected by natural selection (Bennett 1987; Jayne \& Bennett 1990). To date, most studies of repeatability have concerned locomotory characters such as sprint speed and endurance, and there has been a strong emphasis on ectothermic vertebrates (e.g. Putnam \& Bennett 1981; Garland 1985; Arnold \& Bennett 1988; Van Berkum et al. 1989; Austin \& Shaffer 1992). A few studies have examined mammalian locomotion (Ryan 1975; Tolley, Notter \& Marlowe 1983; Djawdan \& Garland 1988). Results from these investigations demonstrate that locomotory performance may be quite repeatable, even in wild populations and across considerable portions of life span (Huey \& Dunham 1987; Van Berkum et al. 1989). Unsurprisingly, several studies suggest that repeatability is highest when measured over short intervals and declines or disappears over extended time periods (Van Berkum et al. 1989; Jayne \& Bennett 1990; Shaffer, Austin \& Huey 1991; Austin \& Shaffer 1992).

Little is known about repeatability of aerobic respiration, even though this trait, the metabolic foundation for power production, is widely studied by both mechanistic and ecological physiologists. Adaptive evolutionary change of aerobic capacity in response to ecological or environmental factors, and its role in setting sustainable limits for locomotion, thermoregulation, reproductive effort and other ecologically important activities, have been the subjects of intense interest and discussion. Fundamental to many arguments about aerobic performance is that it evolved under the influence of natural selection. However, mechanisms of selection are unclear because in many species metabolic rates are known to change rapidly when individ- 
uals are subjected to conditioning regimes or temperature acclimation. This plasticity may profoundly influence the degree to which individual performance is repeatable and hence how selection affects aerobic physiology. For example, acclimatization and conditioning might produce changes in absolute performance but leave relative performance rankings (and hence relative fitness) of individuals unchanged, or it might affect both absolute values and ranking. We are aware of only three studies that have examined the repeatability of aerobic metabolism in vertebrates. Maximal rates of oxygen consumption are repeatable over short intervals ( 1 day) in young Garter Snakes (Garland \& Bennett 1990). In captive Deer Mice, Hayes (1989a,b) and Hayes \& Chappell (1990) found significant repeatability in maximal oxygen consumption (measured as relative performance ranking) over periods from a few days to as long as several months and across several acclimation regimes.

Here we report the results of repeatability studies on the aerobic performance of free-living Belding's Ground Squirrels, Spermophilus beldingi Merriam. We discuss repeatability over intervals ranging from $2 \mathrm{~h}$ to 1 or 2 years. To our knowledge, this is the first examination of repeatability of aerobic traits in a free-living wild mammal. In previous work we described natural variance in aerobic performance and the relationship between minimal and maximal aerobic metabolism in Spermophilus beldingi, as well as changes in aerobic capacity and factorial scope during ontogeny (Chappell $\&$ Bachman 1995). These data provide a useful context within which to examine repeatability.

\section{Materials and Methods}

\section{StUdy Site AND ANImals}

Belding' s Ground Squirrels inhabit meadows and adjacent areas of trees and shrubs in the Sierra Nevada mountains of California (Sherman \& Morton 1984; Bachman 1993, 1994). All individuals hibernate for 8-9 months; reproduction, growth and energy acquisition occur during the spring and summer. During late June to mid-July 1992, 1993 and 1994, we studied a population at the Sierra Nevada Aquatic Research Laboratory (SNARL), a University of California reserve at 2,160 m elevation on the eastern slope of the Sierra Nevada (Convict Creek, Mono County). At this time of year at SNARL, adult females had ceased lactating and all sex and age classes were active. Live-trapping and handling procedures were as described in Chappell \& Bachman (1995). Squirrels were permanently marked with toe-clips in 1992 and earlier (Bachman 1993), and with subcutaneous passive integrated transponder (PIT) tags (Destron, Inc., Boulder, Colorado) subse- quently. We marked squirrels temporarily with black hair dye (Bachman 1993).

\section{Metabolic Measurements}

We measured oxygen consumption $\left({ }^{\mathrm{V}} \mathrm{O}_{2}\right)$ using open-circuit respirometry. The system and protocols are described in detail in Chappell \& Bachman (1995). In brief, we measured maximal $\mathfrak{V}_{\mathrm{O}_{2}}\left(\vec{V}_{\mathrm{O}_{2 \max }}\right)$ during both intense exercise and acute cold exposure. Exercise $\mathrm{V}_{\mathrm{O}_{2 \max }}$ was elicited in an enclosed motorized running wheel. We ran squirrels at gradually increasing speeds until they could no longer maintain position or until $\mathrm{V}$ $\mathrm{O}_{2}$ did not increase with increasing speed. Thermogenic $\mathrm{V}_{\mathrm{O}_{2 \max }}$ was determined at moderately cold ambient temperatures $\left(T_{a}-15\right.$ to $\left.5^{\circ} \mathrm{C}\right)$ using a $79 \%$ helium, $21 \%$ oxygen gas mixture (helox) to produce high rates of heat loss (Rosenmann \& Morrison 1974). Squirrels were exposed to declining Ta until $\mathrm{V}_{\mathrm{O}_{2}}$ began to decrease, whereupon measurements were terminated. To compensate for the mixing characteristics of the chambers, we used the 'instantaneous' ${ }^{\prime} \mathrm{O}_{2}$ calculation (Bartholomew, Vleck \& Vleck 1981). Thermogenic and excercise $\mathrm{V}_{\mathrm{O}_{2 \max }}$ were computed as the highest $\mathrm{V}_{\mathrm{O}_{2}}$ averaged over continuous 1- and 2-min intervals.

\section{StATISTICS}

Repeatability is assessed from the relationship between initial and final measurements. However, a mass correction is necessary because $\mathrm{V}_{\mathrm{O}_{2}}$ is highly dependent on mass. In our study we were dealing with a five-and-a-half-fold range of mass and the mass of individuals often changed substantially between measurements. The relationship between mass and metabolism in Belding's Ground Squirrels has a sharp inflection and is best expressed with two-phase regressions after $\log _{10}$-transformation of both variables (Nickerson, Facey \& Grossman 1989; Chappell \& Bachman 1995). This procedure objectively determines the 'join point' between the two linear segments that best fit the data. To calculate repeatability for data sets with masses spanning join points, we used two-phased regressions to obtain residuals for each individual for both initial and final measurements. For data sets with masses entirely on one side of join points (adults only), we used simple least squares regressions to obtain residuals. For either regression procedure, a significant positive correlation between initial and final residuals indicates significant repeatability. In essence, this approach tests the hypothesis that an individual's relative performance ranking for the initial measurement (with respect to a mass-corrected sample mean) is a signifi- 
cant predictor of its relative performance ranking for the final measurement. All analyses were performed with Statistica/Mac software (StatSoft, Inc.). The significance level was $P=0.05$.

\section{Results}

We studied repeatability over three intervals. Shortterm measurements ( $2 \mathrm{~h}$ between tests) were used primarily to ascertain equipment and protocol reliability (see Discussion). Medium-term (6-18 days between tests) and long-term (1-2 years between tests) measurements were used to assess individual consistency over time. For both exercise and cold exposure protocols the $\mathrm{V}_{\mathrm{O}_{2 \max }}$ averaged over 2 min was slightly smaller than the $\mathrm{V}_{\mathrm{O}_{2 \max }}$ averaged over $1 \mathrm{~min}$ (Chappell \& Bachman 1995). Nevertheless, data from both averaging intervals yielded essentially identical results in repeatability tests. Accordingly, we present data for 1 min averaging intervals only.

We performed short-term studies on 28 squirrels each for exercise and thermogenic ${ }^{\mathrm{O}_{2 \max }}$ (eight individuals were used for both sets of measurements but the different tests were separated by several days). The mass range was 103-415 $\mathrm{g}$ for exercise ${ }^{\mathrm{O}_{2}} \mathrm{~m}_{\mathrm{T}}$ and 100-413 $\mathrm{g}$ for thermogenic ${ }^{V_{O}}{ }_{2 \max }$. Final values of ${ }^{2} \mathrm{O}_{2 \max }$ were significantly lower than initial values for both exercise and thermogenesis (Figure 1a; $P<0.001$ for both; paired $t$ test) but the two measures were highly repeatable both in absolute value (Figure 1a) and as mass-corrected residuals (Figure 1b). Correlation coefficients $(r)$ for initial vs. final $\mathrm{V}_{\mathrm{O}_{2 \max }}$ were $0-98$ for thermogenesis and 099 for exercise $(P<0.001$ for both protorols $)$. For initial vs. final residuals, $r=0.88$ for exercise $V_{\mathrm{O}_{2 \max }}$ and 0.73 for thermogenic ${ }^{\mathrm{V}_{2}} \mathrm{O}_{2 \max }(P<0.001$ for both protocols $)$.
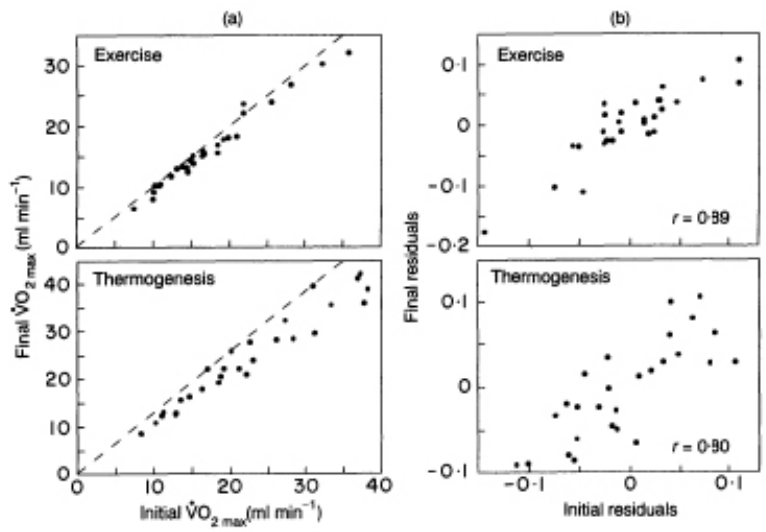

Figure 1. Short-term rapeatability (over a $2 \mathrm{~h}$ interval) of maximal oxygen consumption $1 \mathrm{O}_{2 \max }$ ) in Belding's Ground Squirrels. (a) Initial vs final values of ${ }^{-} \mathrm{O}_{\text {max }}$ as elicited by exercise and thermogenesis. The dashed diagonal lines indicate equivalence of initial and final measurements. Note that repeatability is high, although final values tend to be smaller than initial va! 1es, perhaps because of fatigue. (b) Residuals of regressions of $\log _{10} \mathrm{~V}_{\mathrm{O}_{2 m}}$ on $\log _{10}$ body mass (initial vs. final values) are significantly correlated for both exercise and thermogenesis $(P<0.001$ for both) but the correlation is higher for exercise.

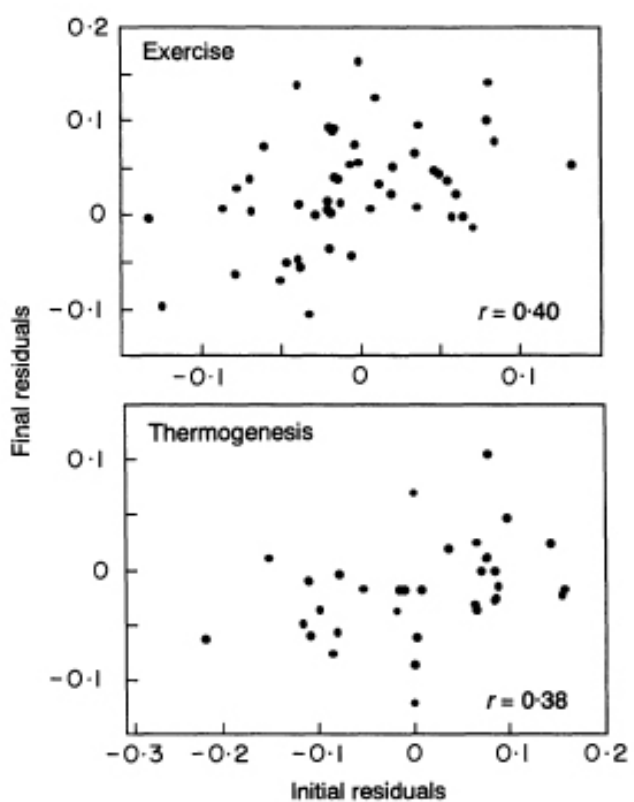

Figure 2. Medium-term repeatability (over intervals of 5-18 days) of $\mathrm{V}_{\mathrm{O}_{2 \max }}$ is significant for both exercise $(P=0.004)$ and thermonnesis $(P=0.03)$. The figure shows residuals of regressions of $\log _{10}{ }^{2} \mathrm{O}_{2 \max }$ on $\log _{10}$ body mass for initial and final values.

Although medium-term repeatability was lower than for short-term studies (Figure 2), it was significant for exercise $(r=0.40, P=0.004, n=50)$ and marginally significant for thermogenesis $(r=0.38, P=0.03, n=34)$. Because the sample included rapidly growing juveniles as well as adults, the mass range was wider for the initial measurements (83-368 $\mathrm{g}$ for thermogenesis; 83-390s $\mathrm{g}$ for exercise) than for the final measurements (136-388g for thermogenesis; $136-390 \mathrm{~g}$ for exercise).

Because of dispersal and high overwinter mortality, the number of between-year recaptures was small (Figure 3). More than half of these data were from squirrels initially studied as juveniles. Because all individuals in the final sample were at least 1-year old, the mass range was considerably wider for initial measurements (89-398 $\mathrm{g}$ for both exercise and thermogenesis) than for final measurements (205-398 g) for thermogenesis; 205-413 $\mathrm{g}$ for exercise). When data from all long-term recaptures (juvenile to adult and adult to adult) were pooled, there was no evidence of repeatability for cold exposure ${ }^{V} \mathrm{O}_{2 \max }(r=0.024, P=0.9, n=$ 19). The correlation for exercise ${ }^{V} O_{2 \max }$ was marginally significant $(r=0.47, P=0.03, n=21)$.

Squirrels first measured as juveniles and subsequently as adults showed no between-year repeatability for either exercise or thermogenic ${ }^{V} \mathrm{O}_{2 \max }(n=11 ; P>0.2$ for both). For the small number of animals tested only as adults (Figure 4), between-year repeatability was marginally significant for exercise ${ }^{\mathrm{V}} \mathrm{O}_{2 \max } r=0.71, P=0.03$, 


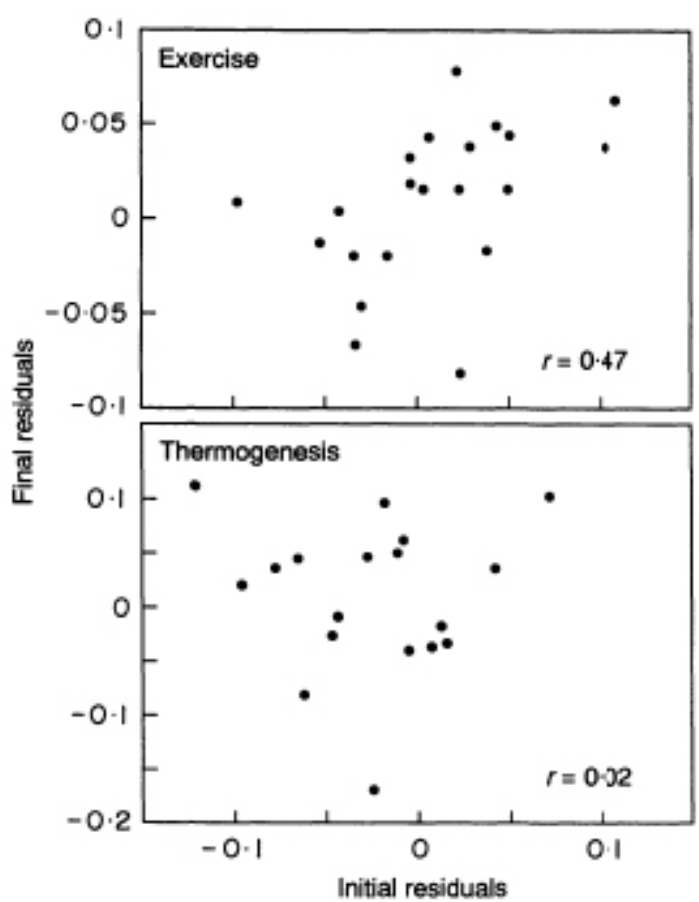

Cigure 3. Long-term repeatability (over intervals of 1 or 2 years) of $\mathrm{V}_{\mathrm{O}_{2 \max }}$ is marginally significant for exercise $(P=0.03)$ but not for therm. genesis $(P>0.9)$. The figure shows residuals of regressions of $\log _{10} \mathrm{~V}_{\mathrm{O}_{2 \max }}$ on $\log _{10}$ body mass for initial and final values. All age groups (individuals initially tested as juveniles and individuals tested only as adults) are included in the figure.

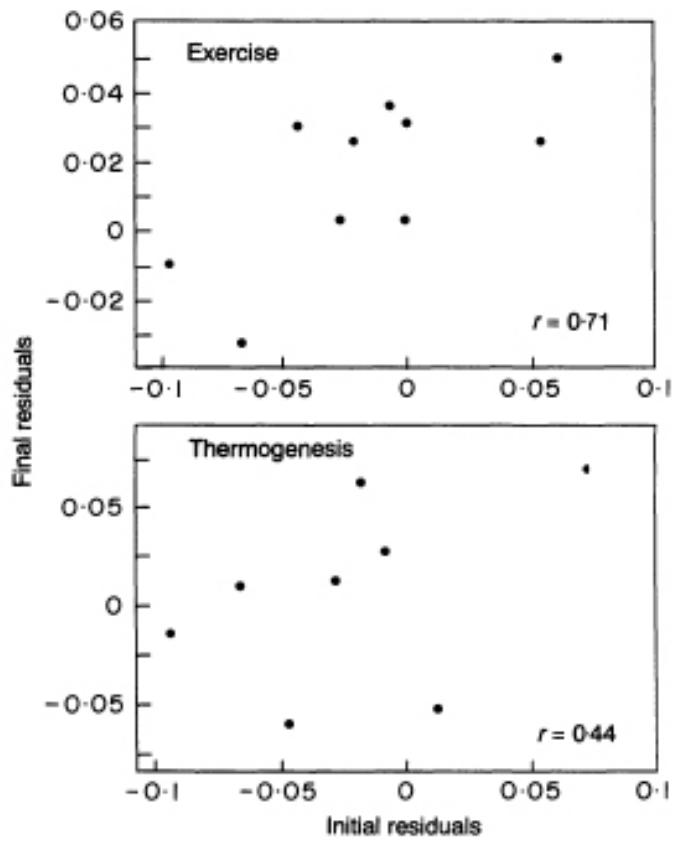

Figure 4. Long-term repeatability (over intervals of 1 or 2 years) of $\dot{V}$ $\mathrm{O}_{2 \max }$ in adult animals is significant for exercise $(P=0.03)$ but not for thermognesis $(P=0.28)$. The figure shows residuals of regressions of $\log _{10} \mathrm{~V}_{2 \max }$ on $\log _{10}$ body mass for initial and fina1. values. Note that removal of any of the 10 data points for exercise $\mathrm{V}_{\mathrm{O}_{2 \max }}$ results in loss of significance. $(n=10)$ but lacked significance for thermogenic ${ }^{2} \mathrm{O}_{2 m a x}$ $(r=0.44, P=0.28, n=8$; equipment failure precluded measurements on two animals). We emphasize that our evidence for long-term repeatability for exercise performance is weak: removal of any of the 10 data points produces a non-significant result.

\section{Discussion}

Belding's Ground Squirrels at SNARL have a fairly high factorial aerobic scope that increases significantly (from 5.4 to 7.5 times minimal resting metabolism) during growth from weaning to adulthood (Chappell \& Bachman 1995). Maximal ${ }^{\mathrm{O}_{2}}$ is tightly correlated with body mass; across a five-and-a-half-fold mass range, the mean difference between observed and regression-predicted values of ${ }^{\mathrm{V}_{\mathrm{O}}}{ }_{2 \max }$ is about $10 \%$. At all ages there is little difference between the ${ }^{V_{O_{2 m a x}}}$ elicited by exercise and the ${ }^{V_{O}}{ }_{2 \max }$ elicited by cold exposure.

\section{MeAsurement ReLiabiLity}

The goal of most repeatability measurements is to determine the degree to which individual differences in a trait are consistent over time. Methods for assessing repeatability are conceptually simple but results of these tests must be examined carefully because they are subject to noise from several sources. For tests of maximal physiological capacity such as those discussed in this paper, inconsistencies in performance may be the results of three different factors: (1) lack of accuracy or repeatability in the equipment used to make the measurements; (2) failure of the measurement protocol to consistently elicit maximal performance; (3) physiological changes between measurements (the biological signal of interest).

In our study of Belding's Ground Squirrels, the maximum absolute error in measuring ${ }^{\mathrm{V}_{2 \max }}$ was $4-5 \%$. Most of this imprecision arose from the equipment used to measure and control gas flow rates. Identical flow settings were used for all animals and the flow control equipment was very stable at a given setting. Therefore the relative accuracy of $\mathrm{V}_{\mathrm{O}_{2 \max }}$ measurements (i.e. for comparisons between animals or between repeats for each individual) was higher than absolute accuracy, with a maximum error of $2-3 \%$. That error is much smaller than the mean within-individual variance in the repeatability tests.

The ability of our exercise and cold exposure protocols to reliably elicit ${ }^{V} \mathrm{O}_{2 \max }$ seems clear but is difficult to test directly. The logic behind protocol design is consistent with our understanding of the physiological machinery supporting sustainable metabolic power production. Similar procedures have been widely employed by a 
variety of researchers and are fairly standard for studies of ${ }^{V_{O_{2 \max }}}$ (e.g. Rosenmann \& Morrison 1974; Wickler 1980; Seeherman et al. 1981; Chappell 1984; Hayes \& Chappell 1986; Hayes 1989a,b; Hinds \& Rice-Warner 1992; Sparti 1992; Bozinovic 1992). In Belding's Ground Squirrels these methods produce $\hat{V}_{\mathrm{O}_{2 \max }}$ data that are tightly correlated to mass (Chappell \& Bachman 1995), which is evidence that ${ }^{\mathrm{V}} \mathrm{O}_{2 \max }$ is determined in a consistent manner. Moreover, short-term $\left(2 \mathrm{~h}\right.$ interval) ${ }^{\mathrm{V}} \mathrm{O}_{2 \max }$ repeatabilities are quite high for both exercise and ther-

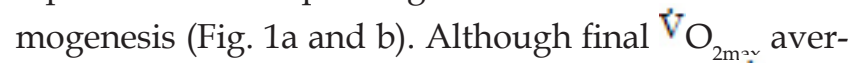
aged slightly but significantly lower than initial ${ }^{V_{O}}{ }_{2 \max }$ the high repeatability indicates consistency in both the protocols' abilities to elicit ${ }^{2} \mathrm{O}_{2 \max }$ and the physiological responses of the animals.

\section{COMPARISON With Other SPECIES}

It is difficult to discuss the repeatability of $\mathrm{V}_{\mathrm{O}_{2 \max }}$ in Belding's Ground Squirrels in a comparative context because to our knowledge repeatability of $\mathrm{V}_{\mathrm{O}_{2 \max }}$ has been reported for only one other mammal and one reptile. Over short periods (1 day), ${ }^{\mathrm{V}} \mathrm{O}_{2 \max }$ is highly repeatable in young Garter Snakes (Thamnophis sirtalis, Garland \& Bennett 1990). In the Deer Mouse Peromyscus maniculatus, $\mathrm{V}_{\mathrm{O}_{2 \max }}$ is repeatable across intervals ranging from 1 day to several months; significant repeatability is also apparent after acclimation to cold and to altitudinal changes (Hayes 1989a; Hayes \& Chappell 1990). These results are consistent with our data for $S$. beldingi. However, the Garter Snake and Deer Mouse studies used captive animals (either laboratory born or wild caught and held in captivity between measurements), which may have influenced results. No between-year data are available for these species.

Most data on the repeatability of physiological performance, and all between-year repeatability measurements, concern locomotor traits (particularly sprint speed). Among a number of species from diverse taxa (primarily reptiles and amphibians but including a few mammals), sprint speed is highly repeatable over periods of hours or days. Typical repeatabilities range from 0.4-0.8, similar to those observed for S. beldingi $\hat{V}_{\mathrm{O}_{2 \max }}$ over $2 \mathrm{~h}$ intervals. Frequently, although not invariably, sprint performance is repeatable over substantially longer periods (reviewed in Austin \& Shaffer 1992). In the lizards Sceloporus merriami and S. occidentalis, speed is significantly repeatable over periods of a year or more and (in contrast to S. beldingi ${ }^{\vee} \mathrm{O}_{2 \max }$ ) across considerable ontogenic growth (Huey \& Dunham 1987; Van Berkum et al. 1989). Racing performance (speed) is repeatable over lengthy intervals in greyhounds (Ryan
1975) and racehorses (Tolley et al. 1983). However, long-term repeatability of sprint speed is low or insignificant for Garter Snakes (Thamnophis sirtalis, Jayne \& Bennett 1990) and Tiger Salamanders (Ambystoma californiense, Austin \& Shaffer 1992). For the latter species, repeatability across metamorphosis is essentially nonexistent (Shaffer et al. 1991). This is analogous to loss of repeatability of $\mathrm{V}_{\mathrm{O}_{2 \max }}$ between the first and second year of life in Belding's Ground Squirrels.

When comparing the repeatability of ${ }^{\mathrm{V}_{2}}{ }_{2 \max }$ with the repeatability of sprint speed, it is important to keep in mind the amount of between-individual variance (upon which repeatability studies are based) in these traits. Variance in the ${ }^{\mathrm{O}_{2 \max }}$ of Belding's Ground Squirrels ( 10\%; Chappell \& Bachman 1995) is reasonably similar to variance in sprint speed in several lizard and mammal species (Huey \& Dunham 1987; Djawdan \& Garland 1988; Van Berkum et al. 1989), but substantially less than for sprint speed and endurance in salamanders (Austin \& Shaffer 1992).

\section{ECOLOGICAL AND EVOLUTIONARY IMPLICATIONS}

This is the first report of repeatability of aerobic performance in a free-living wild mammal. Our findings have implications for studies of the ecology and evolution of aerobic capacity, particularly for examinations of selection on variance (e.g. Jayne \& Bennett 1990) and estimates of its lifetime fitness effects. A fundamental assumption of many studies of physiological adaptation is that performance as measured at one time can be usefully extrapolated to performance at other times. For the ${ }^{\mathrm{V}_{2}}{ }_{2 \max }$ of Belding's Ground Squirrels, that assumption is justifiable over the short-term but is less valid over long periods. In particular, the relative performance of juvenile squirrels cannot be used to predict their relative performance as adults. Evidently there is sufficient phenotypic plasticity and environmental influence during maturation that juveniles with low aerobic capacity can develop into adults with above-average $\vec{V}_{\mathrm{O}_{2 \max }}$ and vice versa. Limited data suggest that adults do show year-to-year consistency in exercise $\mathrm{V}$ $\mathrm{O}_{2 \max }$ however. Larger sample sizes for between-year recaptures will be required to validate these conclusions.

When considering the evolutionary significance of repeatability it is useful to understand the ecological relevance of the trait in question. Without field measurements of selection on aerobic capacity in Belding's Ground Squirrels, it is difficult to quantitatively judge the fitness effects of individual variance in ${ } \mathrm{V}_{2 \max }$. However, observations of intense, sustained activity (such as intermale aggression and long-distance foraging movements; Sherman \& Morton 1984) and reports 
of exposure to severely cold environments (Morton \& Sherman 1978) suggest that a high aerobic capacity is important to Belding's Ground Squirrels. Also, doubly labelled water data from juveniles reveal a mean daily metabolic rate of three times minimal resting metabolism (G. C. Bachman, unpublished data). Approximately 10-12 $\mathrm{h} \mathrm{day}^{-1}$ are spent resting in an insulated nest (personal observations), so average metabolism during the active portion of the day is probably four to five times the minimal rate. That is close to the $\mathrm{V}$ $\mathrm{O}_{2 \max }$ of juveniles (Chappell \& Bachman 1995), suggesting that these squirrels frequently utilize the full extent of their aerobic scope. We conclude that individual differences in $\mathrm{V}_{\mathrm{O}_{2 \max }}$ of the magnitude observed in the SNARL S. beldingi population could influence Darwinian fitness. The fact that $\vec{V}_{\mathrm{O}_{2 \max }}$ is repeatable (in other words, that the performance rank order among individuals is consistent over time) will facilitate any effects of selection on variance in aerobic physiology, provided that aerobic performance is heritable.

The ${ }^{\mathrm{O}_{2 \max }}$ of many small mammals is a rather plastic trait that responds strongly to environmental factors such as exercise conditioning regimes (Hoppeler et al. 1984; Conley et al. 1985), temperature acclimation (Hayes \& Chappell 1986) and capture and captivity (Hayes 1989a,b). Some or all of these processes probably affected the ${ }^{\mathrm{V}_{2}}{ }_{2 \max }$ of the Belding's Ground Squirrels in our study. Moreover, these squirrels hibernate and undergo very large annual cycles of fat deposition and utilization (Morton \& Tung 1971), which might also be expected to impact ${ }^{\mathrm{O}_{2 \max }}$ (but see Chappell \& Bachman 1995). Given this array of potentially confounding factors, the fact that exercise $\mathrm{V}_{\mathrm{O}_{2 \max }}$ shows evidence of repeatability between years (at least in adults) is both surprising and impressive, despite the limitations of our data set.

\begin{abstract}
Acknowledgements
We thank two reviewers, R. Huey and C. Austin, who made several valuable suggestions that improved the paper. Several colleagues at the Sierra Nevada Aquatic Research Laboratory provided valuable assistance during this project. We are particularly grateful to $R$. Gibson, W. Holmes, D. Dawson, S. Roripaugh and J. Shaker. D. Rios and E. Hice fabricated specialized equipment. Collecting and animal-use permits were provided by U.C. Riverside, U.C. Los Angeles, U.C. Santa Barbara, and the California Department of Fish and Game. Our work was supported by U.C. Riverside Intramural funds and equipment obtained under NSF DPP-8917066 to M.A.C.
\end{abstract}

\section{References}

Arnold, S.J. \& Bennett, A.F. (1988) Behavioural variation in natural populations. V. Morphological correlates of locomotion in the garter snake (Thamnophis radix). Biological Journal of the Linnean Society 34: 175-190.

Austin, C.C. \& Shaffer, H.B. (1992) Short-, medium-, and long-term repeatability of locomotor performance in the tiger salamander Ambystoma californiense. Functional Ecology 6: 145-153.

Bachman, G.C. (1993) The effect of body condition on the trade-off between vigilance and foraging in Belding's ground squirrels. Animal Behaviour 43: 233-244.

Bachman, G.C. (1994) Food restriction effects on body composition of free-living ground squirrels. Physiological Zoology 67: 756-770.

Bartholomew, G.A., Vleck, D. \& Vleck, C.M. (1981) Instantaneous measurements of oxygen consumption during pre-flight warm-up and post-flight cooling in sphingid and saturniid moths. Journal of Experimental Biology 90: 17-32.

Bennett, A.F. (1987) Inter-individual variability: an underutilized resource. New Directions in Ecological Physiology (editors, M. E. Feder, A. F. Bennett, W. R. Burggren \& R. B. Huey), pp. 147-169. Cambridge, U.K.: Cambridge University Press.

Bozinovic, F. (1992) Scaling of basal and maximum metabolic rate in rodents and the aerobic capacity model for the evolution of endothermy. Physiological Zoology 65: 921-932.

Chappell, M.A. (1984) Maximum oxygen consumption during exercise and cold exposure in deer mice, Peromyscus maniculatus. Respiration Physiology 55: 367-377.

Chappell, M.A. \& Bachman, G.C. (1995) Aerobic performance in Belding's ground squirrels (Spermophilus beldingi): variance, ontogeny, and the aerobic capacity model of endothermy. Physiological Zoology, in press.

Conley, K.E., Weibel, E.R., Taylor, C.R. \& Hoppeler, H. (1985) Aerobic capacity estimated by exercise versus cold-exposure: endurance training effects in rats. Respiration Physiology 62: 273-280.

Djawdan, M. \& Garland, T. (1988) Maximal running speeds of bipedal and quadrupedal rodents. Journal of Mammalogy 69: 765-772.

Garland, T. (1985) Ontogenetic and individual variation in size, shape, and speed in the Australian agamid lizard Amphibolurus nuchalis. Journal of Zoology, London 207(A): 425-439.

Garland, T. \& Bennett, A.F. (1990) Quantitative genetics of maximal oxygen consumption in a garter snake. American Journal of Physiology 259: R986-R992.

Hayes, J.P. (1989a) Field and maximal metabolic rates of deer mice (Peromyscus maniculatus) at low and high altitudes. Physiological Zoology 62: 732-744.

Hayes, J.P. (1989b) Altitudinal and seasonal effects on aerobic metabolism of deer mice. Journal of Comparative Physiology 159B: 453459.

Hayes, J.P. \& Chappell, M.A. (1986) Effects of cold acclimation on maximum oxygen consumption during cold exposure and treadmill exercise in deer mice, Peromyscus maniculatus. Physiological Zoology 59: 473-481.

Hayes, J.P. \& Chappell, M.A. (1990) Individual consistency of maximal oxygen consumption in deer mice. Functional Ecology 4: 495503.

Hinds, D.S. \& Rice-Warner, C.N. (1992) Maximum metabolism and aerobic capacity in Heteromyid and other rodents. Physiological Zoology 65: 188-214.

Hoppeler, H., Lindstedt, S.L., Uhlmann, E., Niesel, A., Cruz-Orive, L.M. \& Weibel, E.R. (1984) Oxygen consumption and the composition of skeletal muscle tissue after training and inactivation in the European wood-mouse (Apodemus sylvaticus). Journal of Comparative Physiology 155: 51- 61.

Huey, R.B. \& Dunham, A.T. (1987) Repeatability of locomotor performance in natural populations of the lizard, Sceloporus merriami. Evolution 41: 1,116-1,120.

Jayne, B.C. \& Bennett, A.F. (1990) Selection on locomotor performance capacity in a natural population of garter snakes. Evolution 44: 1,204-1,229.

Morton, M.L. \& Sherman, P.W. (1978) Effects of a spring snowstorm on behavior, reproduction, and survival of Belding's ground squirrels. Canadian Journal of Zoology 56: 2,578-2,590.

Morton, M.L. \& Tung, H.L. (1971) The relationship of total body lipid to fat depot weight and body weight in the Belding's ground squirrel. Journal of Mammalogy 52: 839-842.

Nickerson, D.M., Facey, D.E. \& Grossman, G.D. (1989) Estimating physiological thresholds with continuous two-phase regression. Physiological Zoology 62: 866-887. 
Putnam, R.W. \& Bennett, A.F. (1981) Thermal dependence of behavioural performance of anuran amphibians. Animal Behaviour 29: 502-509.

Rosenmann, M. \& Morrison, P.R. (1974) Maximum oxygen consumption and heat loss facilitation in small homeotherms by He$\mathrm{O}_{2}$. American Journal of Physiology 226: 490-495.

Ryan, J.E. (1975) The inheritance of track performance in greyhounds. Master's thesis--Trinity College, Dublin.

Seeherman, H.J., Taylor, C.R., Maloiy, G.M.O. \& Armstrong, R.B. (1981) Design of the mammalian respiratory system. II. Measuring maximum aerobic capacity. Respiration Physiology 44: 11-23.

Shaffer, H.B., Austin, C.C. \& Huey, R.B. (1991) The consequences of metamorphosis on salamander (Ambystoma) locomotor performance. Physiological Zoology 64: 212-231.

Sherman, P.W. \& Morton, M.L. (1984) Demography of Belding's ground squirrels. Ecology 65: 1,617-1,628.
Sparti, A. (1992) Thermogenic capacity of shrews (Mammalia, Soricidae) and its relationship with basal rate of metabolism. Physiological Zoology 65: 77-96.

Tolley, E.A., Notter, D.R. \& Marlowe, T.J. (1983) Heritability and repeatability of speed of 2- and 3-year old standardbred racehorses. Journal of Animal Science 56: 1,294-1,305.

Van Berkum, F.H., Huey, R.B., Tsuji, J.S. \& Garland, T. (1989) Repeatability of individual differences in locomotor performance and body size during early ontogeny of the lizard, Sceloporus occidentalis (Baird and Girard). Functional Ecology 3: 97-105.

Wickler, S.J. (1980) Maximal thermogenic capacity and body temperatures of white-footed mice (Peromyscus) in summer and winter. Physiological Zoology 53: 338-346.

Received September 15, 1994; accepted November 21, 1994. 